\title{
INTERthesis

\section{A LEGISLAÇÃO QUE IMPACTA A POLÍTICA URBANA: CONFLITOS E DIÁLOGO}

\section{THE LEGISLATION THAT IMPACTS URBAN POLICY: CONFLICTS AND DIALOGS}

\section{LA LEGISLACIÓN QUE IMPACTA LA POLÍTICA URBANA: CONFLICTOS Y DIÁLOGOS}

\author{
Angela Moulin Simões Penalva Santos ${ }^{1}$ \\ Marlene de Paula Pereira ${ }^{2}$
}

\section{RESUMO:}

Em razão de conflitos entre as leis que tratam dos temas urbano e ambiental e da escassez de recursos para realização de obras de infra-estrutura urbana estabelece-se uma prejudicial competição no federalismo brasileiro. Embora a Constituição da República Federativa do Brasil estabeleça regras de competências comuns para que todos os entes federativos possam atuar na resolução de problemas urbano-ambientais, nota-se que há uma tendência a transferir a responsabilidade para o município, visto ser este o ente que deve implementar o interesse local. Neste trabalho defende-se a necessidade de que os municípios componham novos arranjos federativos, pautados na cooperação, para que possam superar tais problemas.

Palavras-chave: Legislação. Problemas ambientais. Infraestrutura. Recursos.

\section{ABSTRACT:}

Due to conflicts between laws which rule urban and environmental issues and the scarcity of resources to carry out urban infrastructure constructions, a harmful competition in the Brazilian federalism has been established. Although the Constitution of the Federative Republic of Brazil establishes rules of joint power so that all of the federative bodies can act in the solving of the urban-environmental problems, one can notice that there is a tendency to transfer the responsibility to the municipality, since this is the body which must implement the local interest. In this paper, the authors safeguard the municipalities' need to comprise new federative arrangements based on cooperation, so that they can overcome such problems.

Keywords: Legislation. Environmental problems. Infrastructure. Resources.

\footnotetext{
${ }^{1}$ Doutora e pós- doutorado em Arquitetura e Urbanismo pela Universidade de São Paulo (USP). Professora Associada da Faculdade de Ciências Econômicas e dos Programas de Pós-Graduação em Economia e em Direito da Universidade do Estado do Rio de Janeiro (UERJ). E-mail: angelapenalva@terra.com.br

${ }^{2}$ Mestre em Direito da Cidade pela Universidade do Estado do Rio de Janeiro (UERJ) Especialização em Direito Agrário e Ambiental pela Universidade Federal de Viçosa e graduação em Direito pela mesma instituição. E-mail: depaulamarlene@yahoo.com.br
}

R. Inter. Interdisc. INTERthesis, Florianópolis, v.7, n.1, p. 145-169, jan./jul. 2010

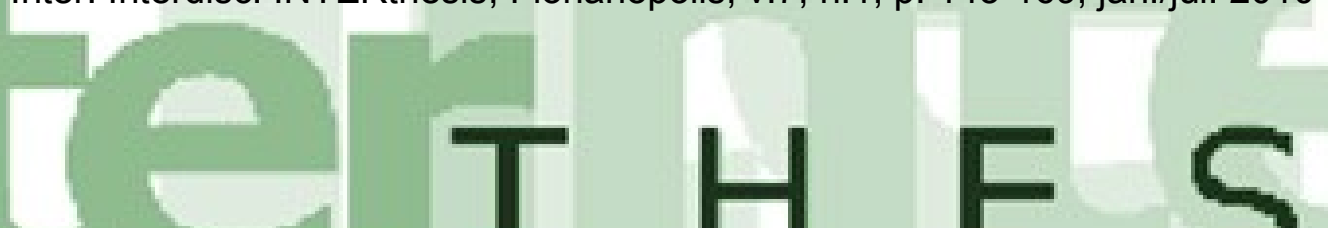




\section{RESUMEN:}

Debido a los conflictos entre las leyes que abordan las cuestiones urbana y ambiental y la falta de recursos para la ejecución de obras de infraestructura urbana se establece una competición perjudicial en el federalismo brasileño. Aunque la Constitución de la República Federativa de Brasil establezca reglas de competencias comunes para que todas las entidades federativas puedan actuar en la resolución de los problemas urbanoambientales, se observa que hay una tendencia a trasladar la responsabilidad al municipio, visto ser esta la entidad que debe implementar el interés local. Este estudio sostiene la necesidad de que los municipios construyan nuevas disposiciones federativas, basadas en la cooperación, para que puedan superar tales problemas.

Palabras clave: legislación. Cuestiones ambientales. Infraestructura. Recursos.

\section{INTRODUÇÃO}

Com o aumento da população urbana, das relações interurbanas e da demanda por moradia e serviços, as cidades brasileiras passaram a enfrentar problemas cada vez maiores, isto é, que ultrapassam os limites territoriais do município.

A solução para problemas de tais proporções também precisa ser ampla. No entanto, obstáculos de diversas ordens inviabilizam medidas conjuntas. Os conflitos vão desde as competências dos entes federativos, dispostas na Constituição Federal, que não são bem definidas, passando por contradições observadas entre as leis que tratam das temáticas urbana e ambiental, chegando a empecilhos decorrentes do modelo federativo adotado pelo Brasil.

Uma competição observada entre os entes, existente principalmente em razão da escassez de recursos para implementar suas competências formais, vem acarretando um 'jogo de empurra' extremamente prejudicial à coletividade como um todo, especialmente à população que habita os grandes centros.

Um tratamento real e efetivo para os problemas mencionados demanda atuação conjunta e compartilhada entre os entes, que busque superar as limitações através de formas alternativas de gestão, mais democráticas e solidárias.

O presente trabalho pretende explicitar a forma como esses conflitos se estabelecem, com vistas a refletir a respeito dos mecanismos existentes na legislação que possibilitam a superação dos obstáculos, efetivando o diálogo. Desse modo, inicialmente será feita breve abordagem a respeito da competência dos entes federativos estabelecida pela Constituição Federal; a seguir, passa-se a analisar conflitos entre as leis federais que

R. Inter. Interdisc. INTERthesis, Florianópolis, v.7, n.1, p. 145-169, jan./jul. 2010 
tratam dos temas urbanos e ambientais; e na terceira seção serão abordados os impasses e possíveis soluções para os problemas.

\section{A COMPETÊNCIA EM MATÉRIA AMBIENTAL NO FEDERALISMO BRASILEIRO}

Sabe-se que o Brasil é uma República Federativa, isto é, é formado pela união indissolúvel de estados, municípios e o Distrito Federal. Segundo Barroso (2007), são elementos básicos da ideia de federação a autonomia dos entes federados e a repartição constitucional de competências. Não existe hierarquia na organização federal, porque a cada esfera de poder corresponde uma competência determinada (SILVA, 2006).

De forma geral, o princípio que norteia a distribuição de competências é a predominância do interesse, cabendo à União, por exemplo, as matérias e questões de interesse geral e nacional; aos estados, os temas regionais; e aos municípios os assuntos de interesse local; destaque-se que a Constituição em vigor não deu definição satisfatória ao conceito de interesse local (SILVA, 2006).

Buscando encontrar o equilíbrio e visando oferecer mecanismos para solucionar os problemas atuais, cada vez maiores, foram instituídas pelos constituintes, além das competências exclusivas e privativas de cada ente, a comum e a concorrente, definidas por José Afonso da Silva (2006) como:

Comum: faculdade de legislar ou praticar certos atos em determinada esfera,
justamente e em pé de igualdade com outras, consistindo, pois, um campo de
atuação comum a várias entidades, sem que o exercício de uma venha a excluir a
competência de outra, que pode assim ser exercida cumulativamente (art. 23).
Concorrente: cujo conceito compreende dois elementos: a possibilidade de
disposição sobre o mesmo assunto ou matéria por mais de uma entidade
federativa e a primazia da União no que tange à fixação de normas gerais (art. 24
e parágrafos).

Entretanto, a forma de cooperação entre os entes da federação não foi especificada, o que provoca conflitos e justifica omissões por parte das entidades responsáveis. É o que se observa, por exemplo, em relação à invasão de áreas ambientalmente protegidas e ao crescimento de loteamentos irregulares. O município alega que é competência da União fiscalizar e conter a ocupação da área; a União contesta, afirmando que o uso e ocupação do solo urbano são problemas de interesse

R. Inter. Interdisc. INTERthesis, Florianópolis, v.7, n.1, p. 145-169, jan./jul. 2010 
local, sendo, portanto, da competência do município. A disputa se arrasta, enquanto as ocupações ampliam-se e a degradação aumenta.

Para evitar esse tipo de problema, o art. 23 da Constituição Federal foi acrescido de um expressivo parágrafo, de acordo com o qual lei complementar fixará norma de cooperação entre a União e os estados, o Distrito Federal e os municípios, tendo em vista o equilíbrio do desenvolvimento e do bem-estar em âmbito nacional. Entretanto, a referida lei complementar nunca foi elaborada. Mas será que precisaria ter sido? Se a própria Constituição previu a cooperação e se através desta é possível estender a proteção aos bens relevantes, como, por exemplo, ao meio ambiente, então parece não haver razões para não aplicá-la. A lei complementar poderia, na hipótese, detalhar como a cooperação ocorreria.

As vantagens de uma cooperação entre os entes é que as pessoas políticas poderiam realizar troca de informações, ações conjuntas, a fiscalização poderia ser divida, e o mais importante: a proteção poderia ser mais efetiva.

Mas o que se verifica na verdade é uma grande competição entre os entes, com notável prevalência do interesse federal. Apesar de inexistir hierarquia entre os entes, a União detém o maior e mais importante leque de competências exclusivas, além do que, ao estabelecer as normas gerais, acaba determinado o comando geral das competências, restando pouco espaço para a competência residual. Isso pode ser problemático, considerando-se que normalmente a União desconhece os problemas locais.

Como se observa, a competência concorrente para legislar e comum para atuar têm o objetivo de ampliar a proteção do bem, para isso tornando todos os entes responsáveis por ele de alguma maneira. No entanto, em outra medida, o fato de o campo de atuação de cada ente federativo não ser claramente definido gera problemas como a omissão e o infindável jogo de repasse da responsabilidade de um ente para outro. O que poderia servir para proteger acaba funcionando como argumento para justificar a falta de proteção. O fato representa obstáculo também para o cidadão que deseja encontrar solução para suas pretensões mas não sabe a quem se dirigir.

Em regra, mecanismos cooperativos tendem a depender de iniciativas federais. Segundo Abrucio (2006), o governo central deve repassar funções e realizar a coordenação das ações mais gerais, fornecendo ajuda técnica e financeira aos níveis inferiores, atuando em prol do equilíbrio das regiões. Já os governos estaduais e

R. Inter. Interdisc. INTERthesis, Florianópolis, v.7, n.1, p. 145-169, jan./jul. 2010 
municipais precisam aprimorar sua estrutura administrativa e seus mecanismos de accountability democrática. Todas as esferas de poder devem desenvolver instrumentos e mesmo cultura política vinculados às relações intergovernamentais, em particular no caso do governo central, em razão de seu papel necessariamente coordenador.

Todos os caminhos apontam que a melhor forma de alcançar melhor qualidade de vida para a população, universalizando seus direitos sem esgotar os recursos naturais, é por meio de ações conjuntas.

No atual estágio de desenvolvimento urbano, soluções locais podem ser insuficientes diante do tamanho dos problemas. O caminho, portanto, é, em lugar de conflito político, fazer a celebração de convênios e consórcios, com a definição consensual dos papéis de cada um, compartilhando esforços e buscando soluções possíveis e viáveis.

No tópico seguinte será feita uma análise das principais leis que impactam o meio ambiente urbano. Pretende-se demonstrar que a produção legislativa brasileira, no que se refere à temática urbano-ambiental, carece de harmonia, apresentando-se algumas vezes até contraditória. Além disso, nota-se uma sobreposição dos interesses da União sobre os dos demais entes, que acabam encontrando dificuldades para solucionar problemas locais ou mesmo para partir rumo a soluções mais amplas quando o problema extrapola os limites do território.

\section{A LEGISLAÇÃO QUE IMPACTA A POLÍTICA URBANA: CONFLITOS E DIÁLOGO}

A partir do ano 2000 observou-se significativo processo de institucionalização da questão urbana no país, com a implementação e/ou discussão de leis importantes, como o Estatuto da Cidade; o Sistema Nacional de Habitação de Interesse Social; o marco regulatório do saneamento e o Projeto de Lei de Responsabilidade Territorial. São normas que visam, à luz da Constituição Federal, reforçar a dimensão pública e social da gestão do solo urbano.

Entretanto, apesar de ter havido aumento da produção legislativa a respeito das temáticas urbana e ambiental visando a assegurar o direito à cidade sustentável, observase que o acesso e a fruição de tais direitos ainda não são extensivos a toda a coletividade. As razões que impedem a plena fruição desses direitos são muitas e vão

R. Inter. Interdisc. INTERthesis, Florianópolis, v.7, n.1, p. 145-169, jan./jul. 2010 
desde deficiências na produção legislativa, passando pela falta de vontade política até chegar à preponderância do interesse privado, isto porque assegurar amplamente esses direitos significa interferir no direito à propriedade, o que conflita com os interesses de alguns setores da sociedade.

Nesta seção será feita uma abordagem a respeito de algumas leis que impactam a gestão ambiental das cidades e a política urbana, enfocando pontos de conflito que são possíveis de verificar entre elas.

No âmbito da gestão ambiental urbana, as leis federais que disciplinam a proteção e o uso do meio ambiente que interessam diretamente aos planejadores urbanos são representadas pelo Código Florestal (Lei 4.771/65), pela Lei de Parcelamento Territorial Urbano (Lei 6.766/79), pela Lei da Política Nacional do Meio Ambiente - PNMA (Lei 6.938/81), pelo Estatuto da Cidade (Lei 10.257/01) e pela Lei de Saneamento Ambiental (Lei 11.455/2007), dentre outras. Contudo todas essas leis estão hierarquicamente subordinadas às diretrizes instituídas pela Constituição Federal, nos artigos 182, 183 e 225.

A Política Nacional do Meio Ambiente - PNMA (Lei 6.938/81) funciona como a espinha dorsal do art. 225 da CF, delimitando o que fazer, quem deve fazer e quais instrumentos devem ser utilizados para fazer a política ambiental. A PNMA tem por objetivo a preservação, melhoria e recuperação da qualidade ambiental propícia à vida, visando a assegurar, no país, condições ao desenvolvimento socioeconômico, aos interesses da segurança nacional e à proteção da dignidade da vida humana. Por meio dessa norma torna-se possível estabelecer os limites e a legitimidade das ações de proteção e de conservação ambiental e da avaliação dos impactos provocados pelas atividades humanas, aplicando-se os instrumentos destinados ao seu controle.

A PNMA é uma lei que dialoga com todas as demais leis que tenham por objetivo garantir a sustentabilidade e o equilíbrio ambiental. Assim, nota-se clara conexão entre ela e o Estatuto da Cidade (Lei 10.257/ 01).

O Estatuto da Cidade, que é uma verdadeira mudança de paradigma para o planejamento urbano no Brasil, não só define diretrizes que apontam claramente para o enfrentamento dos problemas sociais urbanos, da sustentabilidade das cidades, do reconhecimento da cidade real, da justa distribuição dos ônus e benefícios do processo de urbanização, como também indica instrumentos que poderão induzir novas lógicas de construção das cidades, tais como: operação urbana e possibilidade de ampliação de

R. Inter. Interdisc. INTERthesis, Florianópolis, v.7, n.1, p. 145-169, jan./jul. 2010 
potencial de construção, ZEIS (Zonas Especiais de Interesse Social), usucapião e concessão de uso.

Com o Estatuto da Cidade, foi dado um passo importante em direção ao resgate da cidadania. Regulamentou-se o art. 182 da Constituição, que determina a obrigatoriedade do plano diretor para cidades com mais de 20 mil habitantes. Esse plano é o instrumento básico da política de desenvolvimento urbano; reforça a condição do município de protagonista na condução dessa política e, portanto, do adequado desenvolvimento da cidade.

No entanto, quando da formulação dos planos diretores, observa-se em geral que o resultado final não é um projeto comum para o bem-estar de todo o município, mas o somatório dos interesses de três grandes blocos: o mercado imobiliário, que defende a ampliação do coeficiente de aproveitamento em determinadas regiões; o setor popular, que defende a implementação das ZEIS e o incentivo à construção de habitações de interesse social, e a classe média, que luta pela manutenção das zonas exclusivamente residenciais. A síntese final ocorre quando cada um dos setores garante seus objetivos principais e acata aqueles que lhe são aparentemente indiferentes (MARTINS, 2006).

Ocorre que, no cômputo final, o mercado imobiliário e as classes médias conseguem assegurar maior parcela de benefícios. Por exemplo: enquanto a aplicação da outorga onerosa é uma forma de captar recursos provenientes da edificação além do coeficiente básico em todo o território da cidade onde isso é permitido, destinando-os a um fundo de desenvolvimento urbano - para infraestrutura e habitação em áreas carentes -, na operação urbana ela é aplicada no mesmo perímetro da operação, o que gera valorização do local e, portanto, retorno ao investidor dos valores pagos sob forma de outorga onerosa. Assim, enquanto a disponibilidade de áreas nesses perímetros for suficiente para atender à demanda do mercado e à capacidade produtiva do setor imobiliário, certamente os investimentos se concentrarão nessas áreas, não aportando recursos ao fundo de desenvolvimento urbano, o que torna o processo de outorga concentrador e não socializador da valorização urbana decorrente dos investimentos públicos e privados realizados (MARTINS, 2006).

Como se observa, um instrumento que se justifica com o argumento de que em áreas onde o mercado imobiliário tem interesse pode ser produzida infraestrutura e melhorias sem necessidade de investimento do Estado, que poderia então direcionar

R. Inter. Interdisc. INTERthesis, Florianópolis, v.7, n.1, p. 145-169, jan./jul. 2010 
recursos para áreas mais carentes, está funcionando exatamente em sentido contrário. Apesar da moderna legislação, na prática a forma de produção do espaço urbano continua resultando da expressa associação dos interesses do capital imobiliário ao Estado.

Os instrumentos que visam a promover a função social da propriedade, evitando a retenção especulativa de imóveis e engendrando benefício coletivo - seja pela maior oferta de imóveis em áreas qualificadas, seja pela redução dos preços -, são os pontos do Estatuto da Cidade que geram maior conflito. Para os proprietários, os instrumentos da lei apresentam-se como afronta a um direito de propriedade; para o setor popular, apresentam-se como processos lentos e desanimadores frente às necessidades (MARTINS, 2006). Este é caso da usucapião especial urbana e usucapião coletiva.

A Constituição de 1988 fez menção ao instituto da função social da propriedade, porém o condicionou à existência de plano diretor e de lei federal regulamentando a matéria. Como resultado, o instituto permaneceu impraticável por treze anos, até a aprovação da Lei Federal 10.257/01 (Estatuto da Cidade), que, por seu turno, manteve o condicionamento à existência de um plano diretor, conforme previa a Constituição, e ainda a procedimentos e sanções aplicáveis apenas de modo sucessivo no tempo, o que reforça o retardo para a aplicação do mencionado instituto.

Outro instrumento previsto pelo Estatuto da Cidade que tem grande potencial socializador do espaço são as ZEIS, que poderiam ser utilizadas para evitar o problema dos assentamentos clandestinos e irregulares, favelas e ocupações informais em áreas ambientalmente protegidas.

As ZEIS são perímetros demarcados em lei onde se aplicam regras especiais para favorecer a produção de Habitação de Interesse Social - HIS - ou para a sua regularização quando se trata de áreas de assentamento informal. Têm por objetivo a inserção da habitação de interesse social no tecido urbano, evitando a remoção e/ou a segregação. Expressam a intenção de rever o conceito de que a habitação popular pode ser ofertada através da construção de grandes conjuntos habitacionais localizados em terrenos baratos, distantes do centro, sem infraestrutura e sem acesso.

As ZEIS, porém, encontram barreiras no confronto da legislação urbanística com a ambiental, porque a regularização, mesmo em ZEIS, submete-se aos parâmetros da Lei Federal 6.766/79 (Lei de Parcelamento Territorial Urbano), considerados praticamente inatingíveis nos contextos concretos. São procedimentos que exigem precedências,

R. Inter. Interdisc. INTERthesis, Florianópolis, v.7, n.1, p. 145-169, jan./jul. 2010 
principalmente de posse e registro, que remetem a aprovação ou a regularização a um hermético círculo vicioso de onde é impossível sair (MARTINS, 2006). Outro obstáculo enfrentado pelas ZEIS é a incompatibilidade com o disposto na Lei Federal 7.803/89, que estendeu a aplicação do Código Florestal (Lei 4.771/65) às áreas urbanas, sujeitando os planos diretores e leis de uso do solo municipais aos princípios e limites que estabelece dentre eles a faixa de Área de Preservação Permanente (APP).

O regime de proteção das APPs é bastante rígido, tendo como regra a intocabilidade, admitida excepcionalmente a retirada da vegetação apenas nos casos de utilidade pública ou interesse social legalmente previstos (Código Florestal e Medida Provisória 2.166-67/01).

No entanto, os empreendedores urbanos ocupam as APPs, com quadras urbanas ou áreas públicas diversas como uso institucional, sistemas de recreação e vias públicas. Argumentam que, como na cidade não existem mais florestas, essa regulamentação não se aplica.

Alguns autores afirmam que nas normas que regulam as APPs estão as interfaces mais mal trabalhadas entre a legislação ambiental federal e a questão urbana, visto que as falhas presentes na legislação são apontadas como um dos fatores que mais contribuem para o descumprimento dessas normas em áreas urbanas. Há quem sustente que os limites são limites máximos e quem afirme que, na verdade, são limites mínimos (ARAÚJO, 2002).

Essa controvérsia se estende pelo entendimento da Lei $6.766 / 79$, que disciplina a maneira como deve ocorrer o parcelamento do solo urbano. O grande problema se encontra no artigo $4^{\circ}$ dessa lei que prevê uma faixa non edificante de 15 metros ao longo dos cursos d'água correntes e dormentes, enquanto o Código Florestal, prevê 30 metros. É importante ressaltar que a Lei 6.766/79 menciona "salvo maiores exigências" que devem ser estabelecidas sobre legislação específica, que é o caso da legislação das APPs (ARAÚJO, 2002).

O Projeto de Lei 1.687/07, em votação no Congresso Nacional e que objetiva uma revisão da Lei 6.766/79, prevê que deve ser respeitada uma faixa mínima de proteção de 15 metros ao longo dos cursos d'água de até dois metros de largura; em alguns casos específicos, as APPs poderão ser utilizadas como espaços livres de uso público ou de uso comum dos condôminos para implantação de infraestrutura destinada a esportes,

R. Inter. Interdisc. INTERthesis, Florianópolis, v.7, n.1, p. 145-169, jan./jul. 2010 
lazer e atividades educacionais e culturais ao ar livre. A redução da faixa de proteção e a possibilidade de uso público vêm causando calorosas discussões, visto que têm sido entendidas como um retrocesso.

Outro aspecto importante capaz de impactar consideravelmente a política urbana é o zoneamento. Através dele, o Poder Público tanto pode ampliar o acesso democrático à cidade quanto torná-la mais injusta e segregadora.

Para Antonio Octávio Cintra, o zoneamento deve, em teoria, derivar de um estudo pormenorizado dos usos atuais e das tendências evolutivas da cidade; deve ser peça de um plano urbano mais amplo, que deverá conter diretrizes para o sistema viário, para as obras de infraestrutura e parâmetros para as densidades desejáveis e toleráveis em cada área da cidade ou da região metropolitana. Os parâmetros serão validados pela referência às características, atuais ou planejadas, do sistema de transportes e da disposição das diversas infraestruturas urbanas (CINTRA, 2006).

No mesmo sentido, Ermínia Maricato afirma que o zoneamento deve regular aquilo que é essencial: restringir os usos incômodos, sem, contudo, desconsiderar outros aspectos, como meio ambiente, saneamento, drenagem, morfologia, fatores culturais e históricos, sistema viário, paisagem construída, enfim, respeitar o que existe na esfera da natureza, da sociedade e do ambiente construído para organizar, a partir da realidade existente, seus problemas e potencialidades, com a participação da população (MARICATO, 2002).

O zoneamento pode contribuir ainda para expandir o mercado habitacional e baratear o custo da moradia. Pode definir áreas de usos mistos de moradia de diferentes faixas de rendas. Pode auxiliar na determinação da finalidade do uso para a moradia social em áreas específicas; nesse ponto, o zoneamento pode dialogar com as ZEIS.

No âmbito da gestão ambiental urbana, deve-se atentar para três tipos de zoneamentos: urbano (incluindo o industrial), ambiental ou ecológico-econômico e hídrico (diagnóstico do regime hídrico das bacias).

O zoneamento urbano tem como finalidade estipular regras quanto à ordenação do espaço territorial urbano, incluindo o zoneamento industrial (Lei 6.803/80), priorizando a segurança sanitária de suas populações. Uma vez mapeado o zoneamento urbano, este integrará o plano, que por sua vez reproduz as potencialidades e restrições ao uso de ocupação do solo.

R. Inter. Interdisc. INTERthesis, Florianópolis, v.7, n.1, p. 145-169, jan./jul. 2010 
O segundo, o zoneamento ambiental, também tratado como zoneamento ecológico-econômico (Lei 4.297/02), tem como objetivo orientar as políticas públicas para a execução das diretrizes constitucionais no que tange ao desenvolvimento sócioeconômico-ambiental. Divide o território em zonas de acordo com a necessidade de proteção, conservação e recuperação dos recursos naturais e do desenvolvimento sustentável.

Por fim, o terceiro tipo de zoneamento: o de uma unidade hidrográfica. Esse zoneamento ou diagnóstico do regime hídrico será integrado ao plano de bacia e será gerido pelo respectivo comitê de bacia hidrográfica.

Atualmente considera-se superada a lógica de realizar o zoneamento a partir da separação de usos e atividades. Certa mistura de usos é importante para a dinâmica da cidade. O que deve orientar a concepção do zoneamento urbano são as relações desejáveis entre cidade e território e a ampliação do acesso à terra urbanizada. Assim, devem ser considerados critérios como restrições à ocupação urbana em áreas ambientalmente protegidas e indução ao adensamento em áreas consolidadas para melhor aproveitamento das infraestruturas instaladas, compatibilização do uso com o grau de impacto e a capacidade da infraestrutura viária etc.

Desse modo, o zoneamento deve estar inserido numa lógica sistêmica em que a regulação do solo urbano se fará pela combinação dos diversos instrumentos previstos no Estatuto da Cidade.

Ocorre que, ao longo de várias décadas, outros critérios direcionaram a gestão das cidades: as obras concentraram-se nas áreas mais centrais das cidades e as periferias não foram preparadas para receber o contingente de pessoas que não tinham condições de estabelecerem-se na cidade formal.

O Estatuto da Cidade afirma expressamente que o direito a cidades sustentáveis compreende o direito à terra urbana, à moradia, ao saneamento ambiental, à infraestrutura urbana, ao transporte e aos serviços públicos, ao trabalho e ao lazer. Por isso, a insustentabilidade é a marca das cidades brasileiras. Existe um grande déficit de moradia, mas não é só isto: a deficiência dos serviços públicos - como transporte e saneamento - amplia o abismo entre as cidades formal e informal. Apenas recentemente esses temas passaram a ser tratados de forma mais integrada, isto é, como assuntos que ultrapassam os limites do interesse local, mas, ao mesmo tempo, devem estar em sintonia

R. Inter. Interdisc. INTERthesis, Florianópolis, v.7, n.1, p. 145-169, jan./jul. 2010 
com as políticas públicas municipais. A Lei de Saneamento Ambiental (Lei 11.455/07) representa um grande passo nesse sentido. O serviço de saneamento é um tema que interessa à municipalidade, mas precisa ser tratado para além do território da cidade, pois sua importância não termina nas divisas do território. A seguir, está uma síntese a respeito dos principais aspectos presentes no novo dispositivo legal.

A Lei 11.455, aprovada em 5 de janeiro de 2007, teve por objetivo estabelecer diretrizes para o saneamento ambiental. Dentre outras inovações, a lei introduziu um novo conceito de saneamento básico, atualmente denominado Saneamento Ambiental, que vinha sendo amplamente debatido. Com a nova lei, a concepção antiga de saneamento como abastecimento de água e esgotamento sanitário foi superada; passou-se a entender que o melhor conceito é o que integra, além das atividades referidas, a drenagem, o tratamento e a disposição final de águas residuais, além do recolhimento, tratamento e a disposição final de resíduos sólidos. Desse modo, o conceito de saneamento passou a incluir os serviços de abastecimento de água potável, esgotamento sanitário, limpeza urbana e manejo de resíduos sólidos, drenagem e manejo das águas pluviais urbanas, a exigência de um plano de ação por parte dos prestadores de serviço e a participação de órgãos colegiados no controle social do serviço de saneamento. Do ponto de vista da sustentabilidade ambiental, isso deve ser considerado um avanço.

Entretanto, muitos dos problemas antigos não foram solucionados pela nova lei. Um deles é a titularidade do serviço. A lei não abordou a questão, referindo-se apenas aos 'titulares do serviço', ou seja, esquivou-se de resolver velho o conflito a respeito de qual ente deve prestar o serviço de saneamento ambiental.

Pela lei, existem duas formas básicas de prestação do serviço público de saneamento: a gestão direta (pelo próprio titular do serviço, mediante um órgão ou a entidade administrativa) e a gestão indireta (com a criação de uma empresa privada pelo titular, como a constituição de uma sociedade de economia mista). Há, ainda, a previsão legislativa da gestão associada dos serviços por convênio de cooperação ou consórcio público. Trata-se de importante mecanismo de racionalização das ações municipais em relação ao saneamento básico, principalmente no caso de municípios que compartilham recursos hídricos oriundos da mesma bacia hidrográfica ou dos municípios que compartilham a infraestrutura de distribuição de água e esgoto sanitário.

R. Inter. Interdisc. INTERthesis, Florianópolis, v.7, n.1, p. 145-169, jan./jul. 2010 
Outro ponto que merece ser mencionado é a obrigatoriedade de que os prestadores de serviços que atuem em mais de um município mantenham sistemas contábeis que permitam registrar e demonstrar separadamente os custos e receitas de cada serviço em cada um dos municípios atendidos.

Cabe ainda comentar a instituição do Sistema Nacional de Informações em Saneamento Básico - SINISA, que tem por objetivo coletar e sistematizar dados relativos às condições de prestação dos serviços públicos de saneamento, disponibilizando ao público, inclusive pela internet, informações, indicadores e estatísticas, de modo a tornar mais eficiente a prestação do serviço. Esse dispositivo, que ainda não se encontra em pleno vigor, está em perfeita consonância com os princípios da Informação e da participação, além de significar mais um mecanismo de gestão em que a participação da sociedade apresenta-se como possível.

A prestação do serviço de saneamento básico é um caso clássico no qual a falta de objetividade dá margem a conflitos potenciais de competência, restando aos intérpretes a responsabilidade de definir, em relação ao evento concreto, qual ente estatal detém a competência para atuar, porque a titularidade para a prestação do serviço de saneamento ambiental no Brasil é produto de uma sofisticada conjugação de técnicas de repartição de competências no Estado federal. O texto constitucional aponta quatro dispositivos que se relacionam com o tema da competência político-administrativa em matéria de saneamento ambiental (BARROSO, 2007).

O artigo 23 da CF enuncia a competência comum da União, estados, Distrito Federal e municípios de promover programas de melhoria das condições de saneamento básico. A norma não se refere à titularidade do serviço, mas à possibilidade de uma ação de quaisquer dos entes estatais visando ao melhor resultado da matéria. A finalidade constitucional é cooperação entre eles, e não a superposição inútil (BARROSO, 2007).

O parágrafo único do art. 23 previu que lei complementar fixará normas para cooperação dos entes, tendo em vista o equilíbrio do desenvolvimento e do bem-estar em âmbito nacional. A exemplo do que se estabelece em relação à proteção do meio ambiente, o constituinte previu a possibilidade de ação conjunta, colocando, ao lado dessa atuação comum, regras de atribuição exclusiva de competência de cada ente (BARROSO, 2007).

R. Inter. Interdisc. INTERthesis, Florianópolis, v.7, n.1, p. 145-169, jan./jul. 2010 
O segundo dispositivo referente à prestação do serviço de saneamento é o artigo 30, que prevê a possibilidade de o município prestar quaisquer serviços de interesse local.

A Constituição Federal define a prerrogativa dos municípios em organizar e prestar, diretamente ou sob regime de concessão, os serviços públicos de interesse local, de forma a realizar o denominado princípio da subsidiariedade, pelo qual todos os serviços de interesse tipicamente local estejam no âmbito de competência desse nível federativo (SANTOS, 2009).

O terceiro dispositivo constitucional pertinente para o debate é o art. 25, que em seu parágrafo $3^{\circ}$ prevê que os estados poderão, mediante lei complementar, instituir regiões metropolitanas, aglomerações de municípios limítrofes, para integrar a organização, o planejamento e a execução de funções públicas comuns. A leitura sistemática não deixa dúvida de que o artigo refere-se ao interesse comum, ou seja, aquele que transcende o municipal e passa a ser considerado estadual.

Assim sendo, conclui-se que cada modalidade de prestação de serviço conceituada como saneamento básico, que tenha início e fim exclusivos no território municipal, é de competência municipal, pela predominância do interesse local. Se o interesse pelo serviço ultrapassar os limites do município, abre-se a prerrogativa de os estados traçarem as diretrizes regionais, respeitados os limites constitucionais.

Não há norma específica que atribua à União competência para a prestação de serviço de saneamento, a não ser a competência concorrente para promover a melhoria de suas condições, prevista no artigo 23, IX e a competência privativa (art. 21, XX) para instituir diretrizes para o desenvolvimento urbano, incluindo o saneamento básico.

No entanto, a respeito da União vale mencionar o artigo 200, IV, de acordo com o qual compete ao Sistema Único de Saúde, além de outras atribuições, nos termos da lei, participar da formulação da política e da execução das ações de saneamento básico. Assim, além de deter competência comum para as ações nessa área, a União deve participar, em conjunto com os demais entes, do planejamento das ações de saneamento e de sua execução, o que poderá ocorrer de forma direta ou indireta, sob a forma de custeio e investimentos financeiros, auxílio técnico etc. (BARROSO, 2007).

Recapitulando, o saneamento básico está dentre as competências privativas da União (art. 22, XX) no que concerne à definição de diretrizes gerais. Aos municípios, ficou configurada a competência privativa no que afete comprovadamente o interesse local (art.

R. Inter. Interdisc. INTERthesis, Florianópolis, v.7, n.1, p. 145-169, jan./jul. 2010 
30, I e V). Compete aos estados, por derradeiro, em respeito à harmonia da estrutura federalista adotada pela Constituição de 1988, e à luz do princípio da subsidiariedade, traçar as normas complementares, pela proximidade da realidade regional.

Por fim, merece ser mencionado o art. 241, com redação trazida pela Emenda Constitucional $\mathrm{n}^{\circ}$ 19, de 04 de junho de 1998; por ele, os entes federados poderão associar-se para prestação dos serviços públicos por intermédio de consórcios públicos e convênios de cooperação.

A questão, complexa por natureza, torna-se ainda mais se considerar que a regulação do uso de recursos hídricos, ao adotar a bacia hidrográfica como unidade básica do sistema, rompe com os limites físicos e políticos dos estados, os quais são utilizados como padrão para as políticas no campo do saneamento.

Muitos outros dispositivos de leis poderiam ser aqui analisados com o objetivo de demonstrar os conflitos que se estabelecem entre as leis, os interesses ou os entes federativos no momento da implementação de políticas públicas. Entretanto, acredita-se que mais importante do que apontar pontos de conflitos é entendê-los e buscar formas de superá-los. Esse é o objetivo do próximo tópico.

\section{COOPERAÇÃO E COMPETITIVIDADE NO FEDERALISMO BRASILEIRO: IMPASSES E SOLUÇÕES PARA OS PROBLEMAS AMBIENTAIS}

A vasta lista de competências concorrentes previstas na Constituição Federal transmite a noção de que o federalismo brasileiro tem caráter mais cooperativo do que competitivo. No entanto, apesar do grande número de competências concorrentes, na prática existem grandes distâncias entre o que prevê a Constituição e a sua aplicação.

Segundo Abrucio (2006), o que ocorre é que cada nível de governo procura encontrar seu papel específico e não há incentivo ao compartilhamento de tarefas e à atuação consorciada. Disso decorre um 'jogo de empurra' entre os entes federativos.

Para Souza (2006), isso ocorre em razão principalmente das diferentes capacidades dos governos estaduais e municipais de implementar políticas públicas, dadas as enormes desigualdades financeiras, técnicas e de gestão existentes. Além disso, a ausência de mecanismos constitucionais que regulem as relações

R. Inter. Interdisc. INTERthesis, Florianópolis, v.7, n.1, p. 145-169, jan./jul. 2010 
intergovernamentais e que estimulem a cooperação torna o sistema altamente competitivo.

É certo que as federações caracterizam-se intrinsecamente pela diversidade e pelo conflito, não devendo a obtenção de padrões de interdependência resultar da eliminação do pluralismo subjacente ao modelo federalista (SOUZA, 2006). Assim, as parcerias intergovernamentais não podem ser fruto do domínio de uma instância em detrimento de outra ou das demais. Trata-se da coordenação federativa, isto é, o equilíbrio entre a competição e cooperação.

Algumas questões são essenciais em qualquer modelo descentralizador (SOUZA, 2006). Uma delas é o desenvolvimento das capacidades administrativas e financeiras dos estados e municípios para que a centralização ajude a melhorar o desempenho da gestão pública. Não se obtêm os possíveis ganhos de eficiência resultantes da desconcentração das atribuições quando faltam os recursos necessários às administrações locais ou quando estas deixam de exercer sua autoridade tributária.

O repasse de funções deve estar acoplado ao desenvolvimento de boas estruturas gerenciais nos níveis inferiores. Uma grande concentração de tarefas no nível federal prejudica a eficiência, pois desmoraliza a descentralização e continua incentivando a recentralização e o paternalismo (SOUZA, 2006).

O acirramento dos conflitos entre os níveis de governo é outra questão que pode prejudicar a descentralização. Muitos desses conflitos surgem em razão da dificuldade, por parte dos governos centrais, de lidar com o que eles interpretam como "perda da autoridade e perda de competências" (SOUZA, 2006).

O grande problema é que o Brasil não estava preparado para a descentralização. É notável que falta atuação conjunta do ente federal com os entes subnacionais. O primeiro, admitindo o repasse de competências sem abandonar o seu papel de coordenação; e os demais desenvolvendo suas estruturas administrativas, seus mecanismos de implementação da democracia em nível local, sem se afastar das diretrizes gerais.

A atuação cooperativa é essencial para auxiliar governos menos capacitados ou mais pobres a realizar determinadas tarefas; para integrar melhor o conjunto de políticas públicas compartilhadas, evitando o jogo de empurra entre os entes; é necessária no combate a comportamentos financeiros predatórios, que repassam custos de um ente à

R. Inter. Interdisc. INTERthesis, Florianópolis, v.7, n.1, p. 145-169, jan./jul. 2010 
nação, assim como na disseminação de informações sobre as fórmulas administrativas bem-sucedidas, incentivando o associativismo intergovernamental (SOUZA, 2006).

No Brasil, os municípios enfrentam grandes obstáculos no momento de solucionar problemas complexos, como são os ambientais e territoriais. A falta de recursos e a falta de relações intergovernamentais são os principais embaraços.

Existe grande quantidade de municípios pequenos, com pouca capacidade de sobreviver apenas com recursos próprios. Além disso, há a cultura que prega a ideia de que os governos locais podem sozinhos resolver todos os dilemas vividos por suas populações; assim, cada prefeito defende seu município como uma unidade legítima e separada das demais - o que é comprometedor em relação aos problemas comuns, micro ou macrorregionais.

Há pouco incentivo aos consórcios municipais. Em vez de cooperação, predomina um jogo no qual os municípios concorrem entre si pelo dinheiro público de outros níveis de governo, lutam por investimentos privados e ainda repassam, algumas vezes, custos para outros entes.

Assim, duas características marcam fortemente a descentralização no Brasil: a primeira é a forma predatória e competitiva como as relações intergovernamentais se desenvolveram; a segunda, que decorre da primeira, é a falta de incentivo ao compartilhamento de tarefas e à atuação compartilhada, o que, acrescido à indefinição dos papéis específicos de cada nível de governo, conduz a um nocivo 'jogo de empurra', observado principalmente em relação à implementação de políticas públicas.

Após a promulgação da Constituição de 1988, os estados ficaram com um quadro de indefinição quanto a suas competências. Esse vazio institucional favoreceu uma posição flexível dos governos estaduais: quando as políticas tinham financiamento da União, procuravam participar; quando não tinham, eximiam-se de atuar ou repassavam as atribuições aos governos locais. Dessa forma, grande parcela dos encargos foi assumida pelos municípios.

Após 1988 ocorreu aumento das receitas de transferência das instâncias federal e estadual para os municípios, conferindo-Ihes maior aporte de recursos sem vinculação determinada, o que possibilitaria a implementação dos projetos de 'interesse local' (SOUZA, 2006). Os municípios experimentaram ainda maior fortalecimento institucional ao passar a ter competência pela administração de seus tributos (SANTOS, 2008).

R. Inter. Interdisc. INTERthesis, Florianópolis, v.7, n.1, p. 145-169, jan./jul. 2010 
Entretanto, o aumento das responsabilidades assumidas pelos municípios em face da diminuição dos gastos federais não foi acompanhada de uma planejada redistribuição de encargos a partir dos governos federal e estaduais para os municipais. A transferência de crescentes responsabilidades aos governos municipais passou a ser percebida como 'municipalização' das políticas, em particular das políticas sociais.

A partir de 1995, a União passou a colocar em xeque a autonomia financeira municipal por meio de uma série de emendas constitucionais que aumentaram as receitas federais sem que os municípios pudessem se beneficiar do aumento do peso da carga tributária, que passou a crescer devido ao aumento das receitas não-partilháveis com os entes subnacionais, fato que limitou as receitas dos municípios (SANTOS, 2008).

De 1995 em diante, portanto, a descentralização e o fortalecimento institucional dos entes subnacionais foram sendo revertidos. A União passou a aumentar seu controle sobre a formulação das políticas públicas, ainda que a execução continuasse a ser responsabilidade dos governos regionais e locais (SANTOS, 2009).

O movimento de descentralização no Brasil foi muito marcado pela tentativa de transferir encargos e responsabilidades do governo central para os municípios; tal transferência não foi acompanhada pela preparação e pelo fortalecimento dos municípios e dos agentes locais. As relações intergovernamentais existentes se dão principalmente nas áreas de saúde e educação fundamental, que contam com diretrizes e recursos federais, mas são implementadas principalmente por municípios (SOUZA, 2006).

$\mathrm{Na}$ área ambiental, esse tipo de iniciativa restringe-se basicamente à gestão de bacias hidrográficas, que conta com a participação de todas as esferas de governo por exigência de legislação federal. Com relação a outros problemas, como gestão territorial e implementação do serviço de saneamento ambiental, as relações ainda são marcadas pelo conflito.

Segundo dados da STN (2007), 8,6\% (447) dos municípios brasileiros considerados (5.174) têm população superior a 50 mil habitantes, mas são aqueles onde vivem $64,2 \%$ dos brasileiros, que sustentam uma economia mais dinâmica, responsável pela arrecadação de $89,9 \%$ de toda a receita própria dos municípios brasileiros tributos (SANTOS, 2009).

A maior parte dos municípios é constituída de pequenas cidades, de base econômica dependente das atividades agropecuárias de alcance local, incapazes de

R. Inter. Interdisc. INTERthesis, Florianópolis, v.7, n.1, p. 145-169, jan./jul. 2010 
serem financeiramente autônomas e, portanto, incapazes de experimentar a descentralização como fortalecimento de seu papel institucional na Federação. Esses pequenos municípios, na verdade, experimentam a desconcentração das políticas que a União definiu como sendo de alcance nacional e para as quais criou fundos que viabilizam a sua execução, como são os casos da educação e da saúde. Tais municípios se ressentem, ademais, até de capacidade técnica para executar bem as políticas (IBGE, 2008).

Com o orçamento praticamente todo comprometido com os investimentos nas áreas da saúde, educação e pagamento de pessoal, a maior parte dos municípios brasileiros pouco realiza nas áreas urbanística e ambiental.

Os dados do Munic 2008 mostram que 19,2\% dos municípios brasileiros possuem conselho municipal de política urbana ou similar; a região onde se verifica a existência de mais conselhos desse tipo é a região Sul (29\% do total), e a que menos apresenta é a Nordeste $(8,7 \%)$. Os conselhos municipais de política urbana são criados pelo poder público municipal mediante lei específica e são utilizados com vistas a garantir a gestão democrática das cidades pela inserção dos cidadãos como colaboradores, cogestores, prestadores e fiscalizadores das atividades da administração pública na área (IBGE, 2008).

A pesquisa acerca da distribuição por tipo de estrutura ambiental mostra que $54,8 \%$ dos municípios dispõem de secretaria municipal em conjunto com outros temas. Outros 28,9\% dos municípios possuem departamento, assessoria, setor ou órgão similar ligado ao tema. E somente 16,3\% contam com secretaria exclusiva (IBGE, 2008). A secretaria exclusiva é observada quase somente em municípios populosos.

Com relação aos recursos específicos para a área de meio ambiente fundamentais para viabilizar qualquer ação da prefeitura na área ambiental -, menos da metade das prefeituras $(37,4 \%)$ dispõe de tais recursos. Assim, entre os municípios com até 5.000 habitantes, $29,6 \%$ têm recursos específicos para a área ambiental. Esse percentual se eleva para $97,3 \%$ entre os municípios com mais de 500.000 habitantes (IBGE, 2008).

Os dados podem ser facilmente interpretados: para que a prefeitura possa atuar na área ambiental, é de suma importância que esteja minimamente estruturada para tal. É muito difícil que o tema meio ambiente tenha espaço na política pública municipal se não

R. Inter. Interdisc. INTERthesis, Florianópolis, v.7, n.1, p. 145-169, jan./jul. 2010 
existir anteriormente esse espaço no organograma da prefeitura, sob a forma de secretaria municipal, departamento, ou órgão similar de meio ambiente.

Certamente municípios populosos enfrentam maior número de problemas ambientais e, por isso, é freqüente implantar secretarias ou departamentos para cuidar do tema exclusivamente.

No entanto, municípios menores e menos populosos também são acometidos por esses problemas, e, embora muitos possuam secretarias que, dentre outros assuntos, englobem o meio ambiente, sabe-se que muito pouco é realizado em termos de medidas efetivas, em função principalmente da falta de recursos. Isso é um problema que pode ser mais bem enfrentado por meio de arranjos possíveis de serem feitos em um federalismo cooperativo. Arranjos que visem a uma articulação das ações e dos recursos dos três níveis de governo.

Algumas medidas de caráter preventivo - como a criação de programas municipais de redução de risco, a elaboração do mapa de risco do município, o apoio à organização das comunidades vulneráveis e a implantação de programas preventivos de defesa civil podem ser efetuadas pelos municípios sem grandes dificuldades, pois prescindem de grande dispêndio financeiro. Mas, mesmo nesses casos, a atuação conjunta e articulada poderá surtir resultados mais proveitosos.

A elaboração de convênios e consórcios apresenta-se como uma chave para a preparação de uma agenda comum e a implantação de intervenções prioritárias em todo o país.

Se, por um lado, a disputa pelos recursos essenciais para a concretização das responsabilidades resulta em conflitos entre os entes, por outro permite a abertura de espaços de negociação nos quais podem ser pactuados critérios e normas para a alocação dos recursos, além de estratégias de implementação de políticas e programas. Trata-se do viés cooperativo do federalismo.

Além de poder conjugar orçamentos de um grupo de municípios, a associação entre municípios permite maior eficiência na mobilização de recursos e na utilização de serviços públicos para os quais é necessária uma escala mínima de operações (em geral superior à população de um município pequeno).

Os problemas ambientais, em regra, demandam uma série de medidas interligadas. Para que a atuação nessa seara seja realmente eficaz, devem ser

R. Inter. Interdisc. INTERthesis, Florianópolis, v.7, n.1, p. 145-169, jan./jul. 2010 
extrapolados os limites territoriais de municípios, estados ou até países. Por exemplo, um problema de qualidade ou oferta de água em uma bacia hidrográfica não pode ser solucionado pela ação de um município isolado. Esse problema só pode ser adequadamente enfrentado unindo-se esforços dos municípios que pertencem a essa bacia. Logo, algum tipo de cooperação entre municípios é fundamental para que vários problemas ambientais sejam enfrentados da forma adequada.

Desde a Constituição de 1988, foram surgindo acordos intermunicipais que permitiam o funcionamento em rede na prestação de serviços, coordenando demandas e ofertas entre municípios vizinhos. Os consórcios intermunicipais difundiram-se, principalmente nas áreas da saúde e de gestão de recursos hídricos. Nesse diapasão, progressivamente soluções associativas foram ganhando força, certamente antecipadas em algumas microrregiões por indução estadual ou pela presença, na cultura local, de elementos favoráveis à cooperação.

Atualmente, no conjunto dos municípios brasileiros, 59,9\% (3.332) participam de articulações intermunicipais. Essa participação também é maior nos municípios mais populosos. O comitê de bacia hidrográfica é o tipo de associação mais frequente entre municípios. A participação em consórcio intermunicipal ocupa o segundo lugar (IBGE, 2008).

Os arranjos territoriais incluem: consórcios municipais; convênios; regiões integradas de desenvolvimento; regiões metropolitanas.

Acredita-se que, embora as regiões integradas de desenvolvimento e a formação de regiões metropolitanas apresentem-se como opções para o enfrentamento conjunto dos problemas que extrapolam os limites e/ou as forças municipais, os convênios e, principalmente, os consórcios públicos são mecanismos de mais fácil aplicação. Isso porque, para a realização destes, não se nota a presença dos obstáculos que acabam dificultando o funcionamento de outros arranjos, como a indefinição do que deve ser entendido como de "interesse metropolitano" ou mesmo outros dilemas ligados à autonomia municipal, que precisa ser compatibilizada com a obrigatoriedade de os municípios aplicarem verbas próprias a determinados serviços e sob a forma definida pelo sistema de planejamento metropolitano. Nos consórcios e convênios, os direitos, deveres, responsabilidades, aplicação de recursos e métodos de controle são previamente ajustados entre os participantes, em uma espécie de contrato.

R. Inter. Interdisc. INTERthesis, Florianópolis, v.7, n.1, p. 145-169, jan./jul. 2010 
Assim, as políticas públicas elaboradas para enfrentar os problemas que se apresentam na sociedade moderna devem visar a um bem-estar geral que inclui equilíbrio ecológico e dignidade social a toda a coletividade. O 'jogo de empurra' que decorre da indefinição das competências federativas é absolutamente incompatível com essa necessidade, de forma que somente um acordo cooperativo entre os entes permitirá a realização de uma agenda comum na qual cada ente abdicará de alguns interesses e assumirá um conjunto de obrigações e responsabilidades previamente definidas, através da realização de um consórcio, de um convênio ou outro tipo de arranjo.

O arranjo político que responde a essa necessidade é o do chamado federalismo cooperativo, que coordena os vários entes políticos na realização das tarefas públicas.

\section{CONSIDERAÇÕES FINAIS}

O aumento da população urbana e da demanda desta em relação a serviços públicos e recursos naturais impõe que decisões sobre disponibilidades locais muitas vezes sejam definidas fora do âmbito local. Nesse sentido, a articulação das políticas públicas é determinante para induzir a configuração sobre os espaços urbanos, sobre o acesso aos recursos naturais e sobre o acesso social aos serviços.

Observa-se que há uma tendência a remeter tudo para a esfera municipal e a confundir ação municipal com o próprio conceito de política urbana. Passa-se a ideia de que, ampliando-se as competências formais do poder municipal, a população venha a ter maior participação na alocação dos recursos nas políticas de interesse local.

Entretanto, isso não corresponde à verdade. A maior parte dos municípios não possui recursos para implementar todas as competências que possui e, com o orçamento quase todo comprometido com educação, saúde e manutenção da máquina administrativa, outras áreas - como infraestrutura urbana e meio ambiente - normalmente não recebem investimentos.

Considerando que, em razão do crescimento desordenado das cidades, os problemas urbanos tomaram proporções para além dos limites territoriais, as soluções também devem seguir as mesmas medidas.

R. Inter. Interdisc. INTERthesis, Florianópolis, v.7, n.1, p. 145-169, jan./jul. 2010 
Adotando-se o federalismo cooperativo, abre-se espaço para uma articulação de competências supletivas e complementares entre as esferas do Estado nas matérias em que as ações não se esgotem plenamente na jurisdição de cada uma dessas esferas.

Assim, a gestão compartilhada apresenta-se como o caminho mais indicado. Em lugar de utilizar as brechas das leis para eximirem-se das responsabilidades, os representantes dos entes federativos devem fazer a celebração de convênios e consórcios, compartilhando esforços.

Além de novos arranjos federativos, outros mecanismos podem ser utilizados com vistas a resolver os problemas. O Projeto de Lei 1.687/07, que tem por objetivo fazer uma revisão da Lei de Parcelamento do Solo (Lei 6.766/79), faz previsão de alguns desses mecanismos, como a regularização fundiária sustentável, a gestão plena e o licenciamento integrado, no qual a autoridade licenciadora estabelece as condições e restrições de natureza urbanística e ambiental que devem ser obedecidos pelo empreendedor, pondo fim, portanto, ao infindável 'jogo de empurra' do órgão licenciador municipal para o estadual e vice-versa.

Cabe mencionar ainda a necessidade de mudança de postura em relação à aplicação dos dispositivos do Estatuto da Cidade. Trata-se de uma lei com grande potencial social que não tem sido aplicada de forma eficiente para buscar alcançar os fins que nortearam a sua elaboração.

Pode-se pensar ainda na possibilidade de aplicação de outros dispositivos, como a implementação de um plano diretor metropolitano, que, embora não possua previsão legal, apresenta-se como um importante instrumento para a gestão de problemas urbanoambientais.

Parece claro que o caminho para a sustentabilidade pressupõe a ação conjunta dos entes federativos e a participação e fiscalização constantes da sociedade civil.

R. Inter. Interdisc. INTERthesis, Florianópolis, v.7, n.1, p. 145-169, jan./jul. 2010 


\section{REFERÊNCIAS}

ABRUCIO, Fernando Luiz. Para além da descentralização: os desafios da coordenação federativa do Brasil. In: FLEURY, Sonia (org). Democracia, descentralização e desenvolvimento: Brasil e Espanha. Rio de Janeiro: Editora FGV, 2006.

ARAÚJO, Suely Mara Vaz Guimarães. As áreas de preservação permanente e a questão urbana. Consultoria legislativa da área XI Meio Ambiente e Direito Ambiental, Organização Territorial, Desenvolvimento Urbano e Regional. Brasília, Câmara do Deputados, Estudo de agosto de 2002.

BARROSO, Luis Roberto. Saneamento básico: competências constitucionais da União, estados e municípios. Revista Eletrônica de Direito Administrativo Econômico, n.11, ago/set/out de 2007. Disponível em <http:// www.direitopublico.com.br>. Acesso em: 05 mar. 2009.

CINTRA, Antonio Octávio. Zoneamento: análise política de um instrumento urbanístico. ANPOCS. Disponível em:

$<$ www.anpocs.org.br/portal/publicacoes/rbcs $0006 /$ rbcs 06 03.htm - 96k> . Acesso em 15 fev. 2009.

IBGE. Pesquisa de Informações Básicas Municipais. Perfil dos municípios brasileiros. Meio Ambiente. Brasília, 2008.

MARICATO, Ermínia. Brasil, cidades. Alternativas para a crise urbana. 2 ed. Petrópolis: Vozes, 2002.

MARTINS, Maria Lucia Refinetti. Moradia e mananciais: tensão e diálogo na metrópole. São Paulo: FAU-USP/FAPESP, 2006.

SANTOS, Angela Moulin S. Penalva. Emendas constitucionais põem em cheque a autonomia municipal no Brasil. In: SANTOS, Angela Moulin S. Penalva. Município, Descentralização e Território. Rio de Janeiro: Forense, 2008.

SANTOS, Angela Moulin S. Penalva. A política urbana nos marcos do federalismo brasileiro. In: ENANPUR, 12., 2009, Florianópolis. Anais... Florianópolis: 2009.

R. Inter. Interdisc. INTERthesis, Florianópolis, v.7, n.1, p. 145-169, jan./jul. 2010 
SILVA, José Afonso da. Curso de Direito Constitucional Positivo. 27 ed. São Paulo: Malheiros Editores, 2006.

SOUZA, Celina. Desenho constitucional, instituições federativas e relações intergovernamentais no Brasil pós-1988. In: FLEURY, Sonia (org). Democracia, descentralização e desenvolvimento: Brasil e Espanha. Rio de Janeiro: Editora FGV, 2006.

STN (2007). Perfil e Evolução das Finanças Municipais 1998-2006. Disponível em: www.stn.gov.br. Acesso em 19 out. 2008.

R. Inter. Interdisc. INTERthesis, Florianópolis, v.7, n.1, p. 145-169, jan./jul. 2010

Artigo:

Recebido em: 17/08/2009

Aceito em: 23/02/2010 